\title{
Metal and Polymer Matrix Composites
}

\author{
NIKHIL GUPTA ${ }^{1,3}$ and TOMOKO SANO $^{2}$ \\ 1.-Composite Materials and Mechanics Laboratory, Mechanical and Aerospace Engineering \\ Department, Tandon School of Engineering, New York University, Brooklyn, NY 11201, USA. \\ 2.-Combat Capabilities Development Command Army Research Laboratory, Aberdeen Proving \\ Ground, Aberdeen, MD 21005, USA. 3.-e-mail: ngupta@nyu.edu
}

The Metal and Polymer Matrix Composites symposium series was founded in 2013 and rotates between the Materials Science and Technology (MS\&T) conference and The Mineral, Metals \& Materials Society (TMS) annual meeting. The 4th edition of this symposium was organized at the MS\&T 2019 conference from September 29 to October 3, 2019 in Portland, Oregon. The symposium is sponsored by the Composite Materials Committee of TMS and attracts papers related to all aspects of metal and polymer matrix composites, including development of composites with novel reinforcements, structure, and properties. The symposium provides a platform for researchers to discuss the current state of the art in composite materials and present their recent results. This collection of papers is inspired by the symposium, but the submissions are not limited to symposium presentations. The selection of papers in this special topic represents the diversity that is expected in this broad topic area.

The composite materials market was estimated to be over US $\$ 90$ billion in 2019 and is predicted to continue growing at a compound annual growth rate of over $7.5 \%$ in the next 5 years. This strong sustained growth is fueled by continued innovations through research, development, and industrialscale manufacturing. Fiber-reinforced composites form the largest share of the composite market, where large-scale structures can be manufactured with thermoplastic and thermoset resin matrices. The next frontier in high-performance composites is expected to be nanocomposites reinforced with fillers and reinforcements such as carbon nanotubes (CNTs), graphene, and nanoparticles. In addition, nanostructured and nanoengineered matrix materials are also expected to further improve the performance.

Nikhil Gupta and Tomoko Sano are JOM Guest Editors for the Composite Materials Committee of TMS.
One of the areas of emerging interest is functional and multifunctional composite materials. ${ }^{1,2}$ In aerospace applications, where composite materials are now widely used for constructing large-scale structures, a further weight reduction challenge is leading to development of functional composites that also have capabilities such as thermal insulation, corrosion resistance, self-healing, self-cleaning, and other functionalities. Research focused on some of these areas will eventually translate into industry practices and continue to fuel the growth of composites. Engineering at nanoscale remains a major current area of interest in the studies included in this focus topic. Several articles have used CNTs and graphene as reinforcement to develop high-performance composites. While earlier studies on the use of CNTs and graphene focused on polymer matrix composites, the metal matrix composites field is catching up, and several papers in this collection demonstrate important advancements.

Although not yet significant in terms of market share, three-dimensionally (3D)-printed composites seem to be capturing attention in many different fields including aerospace and automotive, which are two of the major composite markets. The flexibility of developing complex shapes using a variety of reinforcements is the driver for development in 3D-printing technologies for composite materials. These $3 \mathrm{D}$ printing technologies are also capable of printing composites with gradient in composition and properties along the length or thickness of the specimen.

The interest in carbon-based nanoscale reinforcement is very high as demonstrated by the studies included in this collection. Several different morphologies can be obtained in carbon at nanoscale, for example, CNT, graphene, and particles. Studies show some remarkable properties obtained from these reinforcements. The spectrum of matrix materials includes magnesium alloys, aluminum alloys, and high-entropy alloys. 
In the article "Qualitative and Quantitative Investigation of As-Cast and Aged CNTs/AZ31 Metal Matrix Composites" by Abbas and Huang, the possibility of developing high-performance lightweight magnesium-alloy matrix composites is studied. The article presents the properties of CNT-Mg alloy composites in as-cast and heat-treated conditions. The results show that the ultimate compressive strength and elastic modulus of the matrix alloy were lower in the aged condition. However, reinforcement of CNTs not only significantly improved these properties as the CNT concentration was increased but also resulted in improved properties of aged composites. However, ductility of the composites was found to decrease as the CNT concentration increased. Presence of CNTs resulted in grain refinement due to ageing process, which helped to improve the properties.

"The Effect of the Addition of CNTs on the Microstructure, Densification and Mechanical Behavior in $\mathrm{Al}-\mathrm{CNTs}-\mathrm{Al}_{2} \mathrm{O}_{3}$ Hybrid Nanocomposites" by Toozandehjani et al. reports optimizing of the ball-milling process for dispersion of reinforcement in the matrix alloy and studies the properties of nanocomposites. Microhardness, nanohardness, and elastic modulus were found to increase as the ball-milling time was increased from $0.5 \mathrm{~h}$ to $12 \mathrm{~h}$. Transmission electron micrographs show well-dispersed CNTs in the matrix alloy. In addition, a compaction pressure of $150 \mathrm{MPa}$ was found to be sufficient for the compaction of Al-2CNTs- $10 \mathrm{Al}_{2} \mathrm{O}_{3}$ nanocomposites.

"Physical and Mechanical Properties of Graphene Nanoplatelets Reinforced Al6061-T6 Composites Processed by Spark Plasma Sintering" by Khan et al. presents the results of a study where $0.1 \mathrm{wt} . \%$, 0.5 wt. $\%$, and 1 wt.\% graphene nanoplatelets (GNPs) were added to an aluminum alloy. Transmission electron microscopy and electron backscattered diffraction (EBSD) techniques were used to observe the dispersion of GNPs in the alloy and the effect of these nanoparticles on the texture of the alloy. The nanocomposites containing 0.5 wt.\% GNPs showed the highest tensile strength under the processing conditions used in this work.

"Tensile Properties of Boron Nitride-Carbon Nanosheet Reinforced Aluminum Nanocomposites Using Molecular Dynamics Simulation" by Vijayaraghavan and Zhang reports the results of a computational study on boron-nitride- and graphene-nanosheet-reinforced aluminum matrix composites. Compared with the aluminum matrix properties, both tensile strength and modulus of nanocomposites are found to be significantly higher. The tensile strength is about $75 \%$ higher for graphene-reinforced nanocomposites. The study also reports temperature-dependent tensile properties. The tensile force of boron-nitride- and graphene-reinforced nanocomposites decreased by $20 \%$ and $16 \%$, respectively, when the temperature was increased from $300 \mathrm{~K}$ to $600 \mathrm{~K}$. Nanosheet reinforcement helped to improve the high-temperature tensile property retention in these composites.

"Microstructures, Martensitic Transformation, and Mechanical Properties of TiNi-Based Amorphous-Crystalline Composites" by Wu et al. reports microstructures, martensitic transformation, and mechanical properties of rapidly solidified $\left(\mathrm{Ti}_{46.5} \mathrm{Ni}_{46.5} \mathrm{Hf}_{2} \mathrm{Si}_{5}\right)_{98} \mathrm{Nb}_{2}, \quad\left(\left(\mathrm{Ti}_{46.5} \mathrm{Ni}_{46.5} \mathrm{Hf}_{2} \mathrm{Si}_{5}\right)_{98} \mathrm{~N}-\right.$ $\left.\mathrm{b}_{2}\right)_{99} \mathrm{Al}_{1}$, and $\left(\left(\mathrm{Ti}_{46.5} \mathrm{Ni}_{46.5} \mathrm{Hf}_{2} \mathrm{Si}_{5}\right)_{98} \mathrm{Nb}_{2}\right)_{98} \mathrm{Al}_{1} \mathrm{Sn}_{1}$. A crystalline-amorphous microstructure was observed in the composite. Introduction of both $\mathrm{Al}$ and $\mathrm{Sn}$ into base alloys resulted in compressive yield and fracture strengths to be as high as $1114 \pm 10 \mathrm{MPa}$ and $2470 \pm 15 \mathrm{MPa}$, respectively.

"Compressive Characterization of Hemp FiberEpoxy Matrix Composite for Lightweight Structures" by Xiang et al. presents results of mixing natural hemp fiber with epoxy to create a renewable composite. Quasi-static and high-strain-rate compression experiments were conducted. The results showed that, with increase in hemp content, the high-strain-rates peak stress decreased. However, the high-strain-rate peak stress was roughly twice that of the quasi-static value. The natural fibers present a renewable resource that can be biodegradable after the useful life of a product. The results of this study can help the automotive industry that is using such natural fiber-reinforced composites.

"Effect of Rare Earth Element Yttrium on Structure and Properties of Boron-Containing High-Entropy Alloy" by Wang et al. uses different atomic ratios of the rare earth yttrium in the FeCoNi1.5$\mathrm{CuBY}$ high-entropy alloy. The highest compressive strength, yield strength, and compression ratio were observed when the yttrium ratio was 0.2 in the alloy FeCoNi1.5CuBY0.2. The improvement of the properties was due to solid solution strengthening, grain refinement, and dispersion strengthening mechanisms.

"Fly Ash as a Reinforcement for Improved Mechanical and Tribological Properties of Composites: A Brief Review" by Kasar et al. reviews the progress made in the area of filling metals or polymers with lightweight hollow fly ash particles. Using this environmentally hazardous waste material in developing high-performance composites can save the matrix metal without compromising the mechanical and tribological properties and help to reduce the demand for primary metals. Feasibility has been shown to create functionally graded composites with tailored mechanical and tribological properties where hardness, strength, stiffness, coefficient of friction, and other properties were controlled by means of cenospehre volume fraction, size, and density.

The selected articles included in the present topic represent the focus of the research field in nanoscale reinforcements and natural fiber reinforcement and lightweight alloys. Improved understanding of structure-property correlations for nanocomposites 
can help to design materials for next-generation high-performance applications. As the growth rate of the composite materials industry is expected to be robust for the next 5 years, it is expected that the results presented in the symposium and the special topic of this journal will help researchers and the composites industry.

To download any of these papers, follow the url https://ink.springer.com/journal/11837/72/6/page/1 to the table of contents page for the June 2020 issue (vol. 72 , no. 6).

\section{REFERENCES}

1. M.R. Begley, D.S. Gianola, and T.R. Ray, Science 364, eaav4299 (2019).

2. A. Dorri Moghadam, B.F. Schultz, J.B. Ferguson, E. Omrani, P.K. Rohatgi, and N. Gupta, JOM 66, 872 (2014).

Publisher's Note Springer Nature remains neutral with regard to jurisdictional claims in published maps and institutional affiliations. 